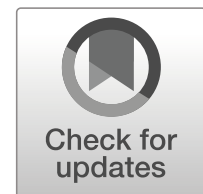

\title{
Flexible Turtles and Elastic Octopi: Exploring Agile Practice in Knowledge Work
}

\author{
Ingrid Erickson* (D), Deepti Menezes, Raghav Raheja \& Thanushree Shetty \\ *Syracuse University, Syracuse, NY, USA (E-mail: imericks@syr.edu; E-mail: demenezes@syr.edu; \\ E-mail: rraheja@syr.edu; E-mail: trshetty@syr.edu)
}

\begin{abstract}
This paper takes as its starting place the rich context of many knowledge workers today — highly distributed, increasing project focused, typically atypical days, infrastructural — and attempts to push past extant descriptions of their practices as 'flexible'. Using empirical data informed by a practice theory lens, we expand the understanding of flexibility with regard to work by augmenting how worker disposition, as well as the ability to engage with agility in dynamic circumstances, should be considered as a factor when examining and designing for this population. We make several contributions of interest to the wider CSCW community. First, we distinguish between those who showcase flexible practices and those who proactively orient around flexibility. We call this second group 'elastic workers'. Second, we raise new questions for us as scholars and designers keen to exploit the conceptual and pragmatic intersection of technology and work. These questions create opportunities to explore different methods for understanding complex phenomena such as flexibility, as well as understanding how we might design for this phenomenon with more foresight in the future.
\end{abstract}

Keywords: Flexible work, Elastic, Knowledge work, Future of work, Practice, Worker, Infrastructure

\section{Introduction}

Studies of knowledge work and the shifting dynamics of knowledge workers are well described in the literature (e.g., Brynjolfsson and McAfee 2014; Cnossen and Bencherki 2018; Spillman and Brophy 2018). As a whole, this body of research documents a professional landscape that is increasingly cognitively-based, expansive (i.e., globalized, inter-organizational), decomposed (i.e., expertise-driven, project based), and reliant on specialized expertise (Barley and Kunda 2006b; Davenport 2005; Spinuzzi 2015). Within this context, it showcases an evolution of workers' practices that CSCW scholars have analyzed for decades. Knowledge workers, such as engineers, architects, digital media consultants, financial 
consultants, and other specialists, increasingly act as 'organizations of one', actively participating in formal ('gig' economy or contract-based work) ${ }^{1}$ and informal labor markets (intraorganizational, see Spinuzzi 2015) to gain terminal project-based assignments in which they interact with multiple clients and collaborators simultaneously (Ciolfi and de Carvalho 2014; Harmer and Pauleen 2012; Kietzmann et al. 2013; Kleinrock 1996; Nylén et al. 2014; Su and Mark 2008; Tilson et al. 2010). More often than not, these assignments, once received, can be executed anywhere in the world, often in modular professional environments like coworking spaces.

There is no one name for this work style or type of worker, and indeed scholars have not necessarily helped to narrow the range of descriptions or monikers. When mobility is a particularly accented aspect of a worker's life, he tends to be labeled as a 'mobile worker'; tautologically, these workers are shown to use mobile infrastructures frequently (Ciolfi and Lockley 2018; Ciolfi and Marc McLoughlin 2017; Cousins and Robey 2015; de Carvalho 2014; Francisco et al. 2018; Koroma and Vartiainen 2018; Yuan et al. 2010). When a worker's mobility spans a wide distance or blurs work-life boundaries, the label is often shifted to 'digital nomad' (Czarniawska 2013; D'Mello and Sahay 2007; Jarrahi et al. 2019; Pittinsky and Shih 2004; Reichenberger 2018). A focus on labor conditions and worker rights, by contrast, tends to underscore the same arrangements as emblematic of a rising 'precariat' (de Peuter 2011; Kalleberg 2018; Milkman and Ott 2014; Osnowitz 2010; Standing 2011). Still other labels relate to other aspects of these workers' professional identities - independent workers, contractors, freelancers, or contract workers.

In this paper, we do not begin with a particular type of worker, but rather aim to understand what have provisionally been labeled as 'flexible' work practices - something that all of the worker types in the paragraph above have been noted to incorporate in one way or another. In particular, we are interested in how workers account for flexibility as part of their own professional momentum, as well as how they describe their flexible strategies in relation to sustaining professional viability. This perspective, like much of the related work within CSCW's canon, adopts a practice perspective. We are not disinterested in the assessment of shifting labor markets, lacking labor laws, or the rise of algorithmic platforms - indeed, any number of salient topics related to the current practices and future expectations of knowledge work motivate this study - but, rather, in this work we aim to augment some of the studies already conducted by this community regarding the complex and dynamic experience of being a contemporary knowledge worker today (Becker 2014).

We decided to position our argument in relation to the concept of 'flexible work' because it encompasses and intertwines many of the aspects of the shifting nature of knowledge work (Kelliher and Anderson 2010). Like this work itself, 'flexible work' is a term that is in flux. Its semantic emphases range from a focus on time to a

\footnotetext{
${ }^{1}$ According to current estimates, $15-30 \%$ of the contemporary workforce in the United States is composed of independent or gig workers (Spinuzzi 2015).
} 
description of new tasks and practices to a labelling of worker type and/or identity. Furthermore, positioning our data analysis in relation to flexible work - and, admittedly, the key rationale for using this term - provides a conceptual connection to our main contribution in this paper: the notion of elastic flexibility. In our discussion of this nascent idea, we describe a type of flexibility that showcases something more than the ability to adapt to new or alternate professional experiences. Rather, describing flexibility as elastic emphasizes an intellectual orientation that is preemptive rather than reactive.

We build our case for elastic flexibility by reporting on a set of interviews with knowledge workers. Our analyses confirm that these individuals engage in many of the same practices that have been well documented by other members of this community such as engaging in self-management activities, coopting spaces for productivity, creatively manipulating time and technology, etc. Establishing these initial empirical synergies allows us to then question why it is that workers do these things and how they account for doing them successfully - which we propose is the result of an orientation to work that is both pre-emptive and reflexive. We label this form of flexibility as 'elastic' to account for the fact that these practices appear to be less a response to dynamic external conditions than a co-construction of external conditions with the internal disposition of the worker. To be elastic, in these terms, is to learn to find stability in dynamic circumstances beyond any one situation, perpetually. We conclude with a discussion of the construct of the elastic worker and what this might mean for the ways that we investigate the future of work, as well as the ways that the human-centered design community might adjust to the phenomenon of elasticity in their consideration and provision of sociotechnical tools and services.

\section{Related literature}

\subsection{Knowledge work as a dynamic, sociotechnical territory}

This study sits at the nexus of the many different fields that investigate the broad relationships between work and technology. Common among these different disciplinary views is the shared reality that, for a hundred years or so, work has been considered something that occurred primarily at singular, formalized locations: the office, in the case of knowledge workers, or the factory, in the case of those involved in manufacturing. These locations were owned and operated by single organizations, most typically, and these organizations centrally managed their employees, their environments, and their information systems (Davies and Frink 2014; Simonton and Montenach 2018). The rise of globalization in the 1980s saw a decrease in the primacy of stand-alone organizational employers and an increase in interorganizational collaborations, which has led to an increase in the diversity and complexity of employees (i.e., interorganizational teams, outsourcing), environments (i.e., offices around the world), and information systems (i.e., the rise of collaboration tools) (Bellotti and Bly 1996; Grudin 1994; Gumienny et al. 2013; Hinds and Kiesler 
2002). In tandem with the distribution and digitalization of work, new platforms and infrastructures emerged to support collaboration, interaction, communication, and other professional collective goals. Today, we see the evolution of these developments in the rise of platforms to support evolved forms of individuated knowledge work, such as gig work (Howcroft and Bergvall-Kåreborn 2018; Wood et al. 2018).

As work has morphed over the last several decades, it has becoming increasingly organized around individual's ownership of tasks (Ekbia and Nardi 2014). This is particularly true of current manifestations of the gig economy (Alkhatib et al. 2017; Prassl 2018), yet even beyond gig work we find more and more people engaged in discrete project-based work today than ever before. Work, in this way, is becoming less defined by the identity associated with ongoing employment, a longterm identification with a specific employer, or even the particular location of a workplace as it is with the achievement an individual finds in accomplishing a set of project goals or tasks. Within knowledge work, in particular, this task-oriented emphasis on work is tightly coupled with the parallel rise in the value of individuated expertise over organizational affiliation (Barley and Kunda 2006b). Knowledge workers have long existed within a professional landscape organized around subject matter expertise (Davenport 2005; Gregg 2013; Spinuzzi 2015), but today individuals' unique stores of knowledge have become solidified as professional currency in an increasingly open marketplace. The spillover effects of this situation reinforce the individual as a set of salable skills and nudge them toward knowledge-driven labor markets (in intraorganizational contexts as well as without) where the currency of this expertise is made obvious. The fact that expertise often gets coded as reputation in today's work environments (Gandini 2016; Origgi 2017) further reinforces the emphasis on the primacy of individual expertise and deemphasizes the complex contexts of work in which these individuals are engaged.

The institutionalization of expertise-oriented labor markets has another impact on workers, particularly when the they work for themselves. These workers must often engage with multiple clients at once; they also typically collaborate with other independent workers in multiple project contexts (Ciolfi and de Carvalho 2014; Harmer and Pauleen 2012; Kietzmann et al. 2013; Kleinrock 1996; Nylén et al. 2014; Su and Mark 2008; Tilson et al. 2010). This puts an onus on them to 'code switch' effectively among their projects and collaborators at any one time, which can be difficult if one's portfolio is highly diverse. The dynamic nature of modern-day knowledge work can also be seen in the transitional infrastructuring practices that individuals take on to accommodate their professional needs. This literature, extensively developed by CSCW scholars, showcases, among other things, how workers appropriate spaces for productivity (Brown and O'Hara 2003; Koroma et al. 2014; Perry et al. 2001), produce personalized infrastructures (Erickson and Jarrahi 2016; Jarrahi et al. 2017; Pipek and Wulf 2009; Rossitto et al. 2014), and strategize to accommodate non-standardized professional circumstances (de Carvalho et al. 2017; Jarrahi and Nelson 2018). While this work forms an important backdrop to this study's understanding of flexibility, we do not review it extensively here as our 
ultimate argument relates less to developing our understanding of these key practices as it does with the acknowledgement that these practices form a backdrop against which worker disposition plays out. This latter point, even in works that emphasize worker motivations (e.g., Ciolfi et al. 2012; de Carvahlo, et al., 2017), is largely overlooked in the literature to date. As such, we aim to augment and extend early discussions around aspects of worker choice regarding flexible practices, following in the footsteps of recent work by de Carvalho and colleagues (2017) in particular.

\subsection{From flexible time to flexible worker}

In many ways it seems obvious to describe these project-driven experts as 'flexible', but that moniker belies a contemporaneous understanding of this term. The concept of flexibility came to prominence around the issue of time (Felstead and Jewson 1999). Initially, the idea referred to making flexible adjustments relative to standard working hours-those hours nominally being 9:00 am to 5:00 pm, though this varies culture to culture. Flexible work, then, noted the alteration to this standard temporal pattern. Typically this was to the employee's personal advantage ${ }^{2}$ as it allowed them to accommodate other important aspects of their lives, such as parenting or other family concerns (Allen et al. 2013; Brandth and Kvande 2001; Carnoy 2000; Hill et al. 2010; Hill et al. 2001; McNall et al. 2010; Perlow and Kelly 2014; Shockley and Allen 2007).

The obvious consequence of blurring the demarcations of 'work time' and 'nonwork time' is the creation 'flex time', which has a porous boundary across which work and personal concerns easily slide (in both directions). When work is not limited to a socially recognized and temporally delimited standard, it requires the worker to engage in a new form of intentional management to shore up those porous boundaries (Ciolfi and Lockley 2018; Cousins and Robey 2015; Mazmanian et al. 2013; Sayah 2013; Wajcman et al. 2008). Possessing 'flex time' also has spatial implications, particularly when work is constituted as a form of telework or remote work. For example, the notion of the home office predicates both temporal as well as spatial boundary making and management on the part of a worker (Gisin et al. 2016; Heath et al. 1995; Kelliher and Anderson 2010; Rossitto and Lampinen 2018). The ability to work from anywhere - the epitome of the modern conception of flexibility - actually puts an onus on a worker to construct or find a physical situation that will be effective for professional productivity. The popular rise of coworking spaces (Bouncken and Reuschl 2016; Garrett et al. 2017; Leclercq-Vandelannoitte and Isaac 2016; Spinuzzi 2012) highlights workers' desires to leverage non-traditional, yet socially sanctioned, workspaces that, among other things, allow them to shore up the spatio-temporal boundaries of their professional lives.

\footnotetext{
${ }^{2}$ This is rising concern about the rise of flexible work schedules, often in retail, that are adjust under a 'just in time' rubric. While this situation will not be considered here, it does point to an understanding of flexible scheduling that is very much not in the hands of the worker.
} 
The field's current understanding of flex workers might be constructively summarized by two key points. The first is that flexible workers act increasingly as expert contractors: because they are well-educated and possess unique skills and experiences, they increasingly operate as project-based contractors or 'companies of one'. This orientation to their work, both within and without permanent employment situations, motivates them be their own managers, to dictate their own terms of work, and to rely on professional and personal networks to advance their careers (Barley and Kunda 2006a; Kalleberg 2000). The second major attribute of the modern flex worker is their need to be agile bricoleurs: as experts, flexible workers need to go where the work is, which leads them into diverse professional contexts and forces them into decisions based on an ever-changing set of professional variables (Humphry 2014; Kakihara and Sørensen 2001; Liegl 2014). Often on the move to interact with clients or pursue collaborations (Su and Mark 2008), flexible workers must leverage the infrastructures and resources in their toolkits with ingenuity and aplomb to be successful (Vertesi 2014).

This improvisational and situational aspect of their work is what constitutes these flexible workers as bricoleurs, a term that sociologist Levi-Strauss (1966) coined to emphasize an ability to work with what was to hand. Ciborra, drawing on LeviStrauss, explains the conditions in which bricolage flourishes:

"As soon as we leave the realm of method, procedure, and systematic ways of organizing and executing work according to rational study, planning, and control, we enter the murky world of informal, worldly, and everyday modes of operation and practice. It is the realm of hacking; practical intelligence; the artistic embroidery of the prescribed procedure; the shortcut; and the transgression of the established organizational order as embedded in systems and formalized routines. 'Bricolage', 'improvisation', and 'hacking' are terms that are often used to describe such modes of operation in various domains of activity. The terms differ slightly in meaning, but they have many aspects in common, of which these modes are among the most important. Since these approaches diverge from the formalized, preplanned ways of operating, their outcomes can well lead to serendipity and to the possibility of finding something valuable that was not sought for at the outset ..." (2004, pp. 20-21)

So this combination of time, space, and technology, set against a backdrop of shifting labor markets and the commodification of professional expertise, appears to be giving way to an emergent understanding of workers themselves, rather than just the conditions of their work, as being flexible (Richardson 2010; Richardson and McKenna 2014). But what do we really understand about how a worker accounts for their own ability to be flexible? We aim to answer to this question in the remainder of this paper. 


\section{Methodology}

The research presented herein is part of a larger initiative to understand how modernday knowledge workers, in their complexity as described at the beginning of this paper, encounter and interact with digital infrastructures. The project was initially funded by an exploratory grant from the United States National Science Foundation in 2013; data collection, primarily in the form of interviews, commenced in 2014 and was completed in 2016. Several products from this research have been previously shared at conferences or published, all emphasizing how workers create digital assemblages and engage in infrastructuring practices (Jarrahi et al. 2019; Erickson and Jarrahi 2016. Several papers will be forthcoming describing the competencies that workers need to engage in these activities. As the work has moved on, the first author has been oriented toward more reflexive considerations, such as questions of methodology (Erickson, 2017) as well as the topic of the current paper, namely the meaning(s) embedded in the concept of flexibility.

\subsection{Data collection}

The broad question that we focus on herein asks: what is the relationship between workers' dispositions and the type of work practices that they engage in? Methodologically speaking, we brought this new question to our existing interview data. This approach both acknowledges past research interests and foci as well as the way that our curiosity has continued to develop as qualitative researchers via continuing engagement with our data. Given that we had a rich dataset to work with, we wondered, after noting the presence of many creative sociotechnical practices in our data, first, how workers themselves accounted for the work practices that they described to us, and, second, how these accounts might help us understand them as 'flexible' workers. These are the core questions that drive the analysis presented herein.

The interview dataset to which we posed these new questions was created by three members of the original research team ${ }^{3}$; two members of the team, Erickson and Jarrahi, engaged directly in data collection. As documented in greater detail in (Erickson and Jarrahi 2016), the theoretical framework used to design and conduct the study was practice theory, namely the emphasis on "recurrent, materially bounded and situated action engaged in by members of a community" (Orlikowski 2000, p. 256). As such, our interview protocol contained many questions about how our subjects went about their work. Sample questions included: 1) Describe the rhythm/patterns of a typical work day for me. 2) Can you describe where you do your work? 3) How do you get online when you need to? 4) Would you be willing to show us what you bring with you regularly to do your work? While the research team conducted 58 interviews in total over total duration of the project, we report here on a subset

\footnotetext{
${ }^{3}$ Erickson (author), Mohammad Jarrahi, Steven Sawyer.
} 
$(N=31)$, which were conducted in our first round of interviews, primarily by the first author.

Given our interest in practice, we created a subject eligibility framework that focused on a combination of the following two criteria: a) individuals who were in control of their own work practices and technology choices (i.e., able to make decisions about the way that conducted their work), and b) individuals with more than episodically mobile practices (i.e., mobile beyond routine commuting, for example). We justified this broad perspective on two fronts. First, we were interested in infrastructural practices and knew from scholarship in fields like CSCW that there are commonalities with regard to technology use that spill beyond industry or profession. We were in pursuit of these commonalities, which would have been precluded if we had pre-determined that we wanted only to focus on a singular profession such as architects or web designers, for example. Second, we knew from literature regarding the changing nature of work that many 'flexible' workers do not work solely for one organization, so choosing to conduct this study in a single organizational setting, which has been typical of the field in the past, posed the risk of eliminating access to a set of actors in which we were particularly interested. The effect of these two conditions meant that we built our sample around the presence/ absence of certain work conditions-personal agency and a dynamic work environment - as a means to best validate our original research interests. While these choices may seem to add indirection to our efforts, on the whole they are in keeping with other studies of practice, particularly within the fields of organizational studies (e.g., Mazmanian and Erickson 2014) and science and technology studies (e.g., Mullan and Wajcman 2017) .

We detail the demographics of our interviewee sample in Table 1; all names listed are psuedonyms. The first author conducted her interviews (first 21 listed) either in person in New York City (NYC) or via the video conference tool, Skype. The last ten interviews in the list were conducted by Mohammad Jarrahi in person in the greater Research Triangle area of North Carolina or via a video conference tool. Only gender and role demographics were collected, so we cannot report on subjects' ages here. All interviews were audio recorded and professionally transcribed. Meenal was also shadowed by the first author for a full day in New York in June 2014, which was documented by field notes and photographs.

A few comments about the two research locations may add additional context regarding the subjects located there. New York City is the financial capital of the United States, but it is also predominant in media and creative industries. Our sample of workers reflects the prevalence of these industries, but individuals were not intentionally chosen to reflect any form of professional diversity quota. The Research Triangle area, by contrast, is defined by the collective research culture that derives from the three universities that make up its points: Duke University, University of North Carolina at Chapel Hill, and North Carolina State University. In contrast to NYC, it is an area well known for its R\&D and high-tech startups, particularly in the medical field. 
Table 1.. Interview subjects.

\begin{tabular}{|c|c|c|c|c|}
\hline Count & Pseudonym & Gender & Position/Role & Knowledge Domain \\
\hline 1 & Meenal & $\mathrm{F}$ & $\begin{array}{l}\text { Founding Principal/Workplace } \\
\text { Consultant }\end{array}$ & arch/workplace design \\
\hline 2 & Mary & $\mathrm{F}$ & $\begin{array}{l}\text { Director of Planning and } \\
\text { Implementation }\end{array}$ & arch/workplace design \\
\hline 3 & Meera & $\mathrm{F}$ & Adjunct Professor & higher education \\
\hline 4 & Linda & $\mathrm{F}$ & Program Coordinator & higher education \\
\hline 5 & Elle & $\mathrm{F}$ & Meetup Director & event planning \\
\hline 6 & Quincy & M & Director of Special Projects & event planning \\
\hline 7 & Priyanka & $\mathrm{F}$ & Freelancer/pedicab driver & arch/workplace design \\
\hline 8 & Kira & $\mathrm{F}$ & Associate Director & arch/workplace design \\
\hline 9 & Rohan & M & Head of Global Security & media \\
\hline 10 & Jay & M & Software & software development \\
\hline 11 & Marianne & $\mathrm{F}$ & Freelance, community organizer & data analytics \\
\hline 12 & Dheeraj & M & Co-Founder \& Financial Director & software development \\
\hline 13 & Shuhei & M & Strategist & $\begin{array}{l}\text { nonprofit strategy } \\
\text { consulting }\end{array}$ \\
\hline 14 & Praharsh & M & Coordinator & event IT (on site) \\
\hline 15 & Chandresh & M & CEO & nonprofit head \\
\hline 16 & Smirity & $\mathrm{F}$ & Director & consultant/head of own firm \\
\hline 17 & Margaret & $\mathrm{F}$ & Researcher & ecologist, foreign travel \\
\hline 18 & Chuck & M & Designer & website design \\
\hline 19 & Felicia & $\mathrm{F}$ & $\begin{array}{l}\text { Independent data visualization } \\
\text { designer and developer }\end{array}$ & information visualization \\
\hline 20 & Ping & $\mathrm{F}$ & Senior Systems Analyst & $\begin{array}{l}\text { software development/client } \\
\text { services } \\
\text { (health care) }\end{array}$ \\
\hline 21 & Misaki & $\mathrm{F}$ & Freelancer & $\begin{array}{l}\text { project management; film } \\
\text { production }\end{array}$ \\
\hline 22 & Blossom & $\mathrm{F}$ & $\mathrm{PhD}$ student and instructor & higher education \\
\hline 23 & Betsey & $\mathrm{F}$ & Web developer & web development \\
\hline 24 & Nilay & $\mathrm{F}$ & $\begin{array}{l}\text { business and communications } \\
\text { strategy consultant }\end{array}$ & $\begin{array}{l}\text { business and strategy } \\
\text { consulting }\end{array}$ \\
\hline 25 & Charlie & M & Knowledge Execution Lead & $\begin{array}{l}\text { business and strategy } \\
\text { consulting }\end{array}$ \\
\hline 26 & Bo & M & Drupal / PHP Developer & web development \\
\hline 27 & Todd & M & Technology Columnist & $\begin{array}{l}\text { communication and content } \\
\text { management }\end{array}$ \\
\hline 28 & Helen & $\mathrm{F}$ & Business Productivity Consultant & $\begin{array}{l}\text { business and strategy } \\
\text { consulting }\end{array}$ \\
\hline 29 & John & M & IT consultant & IT support \\
\hline 30 & Sam & M & Speaker / Conference Catalyst & $\begin{array}{l}\text { communication and content } \\
\text { management }\end{array}$ \\
\hline 31 & Bob & $\mathrm{M}$ & Partner & legal services \\
\hline
\end{tabular}




\subsection{Data analysis}

All interview transcripts were analyzed by the first author and a team of graduate students in the summer and early autumn of 2018. We used standard grounded theory techniques (Glaser and Strauss 1967; Glaser 2017; Morse et al. 2016), iteratively moving from open coding to axial coding through many rounds of collective sensemaking; these are the venues in which we also standardized the meaning of all codes among the members of the research team. While engaging in this task, we utilized various spreadsheets and whiteboards to facilitate our iterative understanding of the semantic categories that were emerging from the data.

Our final six axial codes, inductively determined, represent the full array of themes from the interviews: Background/Context focused on the individual and the industry; Activity intended to capture any sort of activity and practices in spheres of travel, task and time management, communication, problem solving and social interaction; Creating a Workplace was meant to capture how subjects considered certain environments or physical spaces as possible places to do their work; Data Management and Technology Use intended to capture practices or their relation to digital infrastructure and work; and Impediment/Problem tried to highlight factors that were considered by them as possible drawbacks or issues when it came to certain kinds of work practice.

Each of these parent codes possesses a set of more specific child codes, which focus on different dimensions of the parent code. For example, the parent code 'Activity' possesses the following child codes: communication, problem solving, social interaction, task management, time management, and travel/movement. In this example, all of these child codes also had children of their own. In the case of the child code 'communication', for instance, there are the following grandchildren codes: calling by phone, emailing, texting, using social media, videoconferencing. Codes were iteratively applied and reapplied to interview transcripts, once collectively standardized, using the collaborative, cloud-based qualitative analysis tool, Dedoose, by the last three authors.

\section{Findings}

Our findings corroborate much of the research within our community showing how individuals adapt to mobile, nomadic conditions in their professional lives by engaging in self-management practices, using infrastructures and resources creatively, shifting time, and appropriating space. We show these synergies with each of these areas of prior research by providing new empirical detail.

\subsection{Self-management}

Prevalent in our data were examples of flexibility as a form of self-management. This is the flexibility of the tightrope walker, able to walk on air, seemingly, but only with 
the utmost of attention and care. Chuck, a freelance art director, explains this imperative for self-management well:

"I think you develop a lot of management skills because you really do manage your own time in a way that most people don't have to do. Because when you have a job, you go in and have a set of expectations and a set of policies and procedures to get the job done. You don't have to worry about that workload as much as you do if you're a freelancer and all the client is expecting from you is a finished product. Then you have to figure out how to get there yourself."

Getting there, maintaining progress without the grounding of organizational 'policies and procedures' is necessary to find stability in the face of dynamic circumstances. It is the situational capability of routinizing typical atypicality, of not dropping off the wire.

\subsection{Flexible use of infrastructures and resources}

Workers also showcase flexibility with practices surrounding the use of infrastructures and resources, particularly digital assemblages and non-monetary assets. The intrinsic situational variation of our participants' work means, on the one hand, that they have a high degree of liberty and control, but, on the other hand, puts them in the parallel position of having to determine, maintain, and constantly update a set of personalized guidelines to preserve their continued effectiveness as a professional.

Chuck, again, showcases this double-edged agency of flexibility when speaking about how he chooses applications to manage his personal project portfolio:

"I use and I can also bring in tools that my clients use sometimes. There's a service called sunrise.am, it's a calendar app that I've used for years. When it started it was just kind of a simple like novelty app that sort of connected to your Facebook and sent you an e-mail every morning telling you what was on your plate for the day and an inspirational quote or something. I liked that because as time went on it sort of morphed into this very powerful tool. Then I also have it synched to Asana which I use for project management, so it pulls in all my different ... I have a ton of different Asana boards because I have several that I work with my tech.co client, and then I also have three different ones I use for personal stuff for two different types of business, and then just a personal one that kind of serves as like . . I need a reminder to pay the electric bill, that's good. Then I also bring in . . . so like for my other job I'm doing right now, their project management system is sort of, I mean it's very much an internal tool, like it's not anything I would want to synch with my personal stuff. So it's sort of the go between. There is that. Then I manage my day to day tasks at that job with Wunderlist which is another app. So I've got all my different calendars being pulled into one place and especially 
working, especially right now with the one having a lot of deadlines to hit because we're sending things to print for a conference, that calendar is like my lifeline. I start there every morning."

Within this elaborate ecosystem of tools, some integrated with one another, others not, you see the invisible hand of this worker, subtly yet effectively directing inputs into valuable outputs. The vernacular assemblage that he has created between Sunrise.am, Facebook, Asana, Wunderlist and the other tools, however, must be tended to and regularly maintained. There is no IT department doing this for him; he is his own IT department. So, in flexible work terms, with agency comes responsibility.

Apart from using different tools at a workplace, the flexible workers in our study also appear to have a particular acuity when it comes to understanding what may be needed to accomplish their goals when they are on the move or away from their workplace. Contrary to first impression, these needs rarely correlate to the imaginary set of professional technologies that first spring to mind. Instead, they are mundane, often invisible, tools in the broadest sense of the word. Sam, a professional speaker and corporate trainer, reveals one such example:

"[F]inding a table near a plug is hard. I carry ... in my bag I carry an electrical splitter that splits the plug into 3 plugs. I carry it in my bag in case I'm in an airport or in a Starbucks and all the plugs are filled. I can split the plug and make 3 outlets."

Similarly, Smirity, an entrepreneur who runs her own consulting firm, relies heavily on her camera for her work. Yet, what she refers to it as 'important' is an adapter, another mundane tool that plays a vital role in the functionality of her digital assemblage:

“. . . I have some really great little tools for the iPad which are portable tools but they plug into the iPad and I guess they're called adapters and then you can insert a SIM card. So the photos from my hefty Nikon camera can go directly to my iPad once I plug it in and that saves me from having to go home to my laptop, upload photos, and then I can actually post them at the event, high quality, high res photos that I'm taking from my big camera. So that's an important device."

Chuck also gave us a list of tools that he carries in his bag, but only called out one as essential: "I've always been a thumb drive kind of guy. I keep an iPhone cable in my bag usually. .. And a mouse, yeah, I usually have a mouse. That's essential for the kind of work that I do."

We can see from these examples that mundane technologies, like splitters or adapters, are prized by our interviewees, yet are often overlooked in conversations about designing future work technologies. The application of mundane technologies 
within one's professional practice is also not considered part of a worker's domain expertise. In reality, however, knowing the value of these interstitial pieces within the larger puzzle of one's work showcases a deep, substrate-level of knowledge upon which more recognizable forms of domain expertise can exist. In fact, this is a form of meta-expertise - a topic that bears additional attention in our community.

Finally, the flexible workers in our study show that they understand how to use non-technological resources to their advantage as well. Maintaining momentum in the face of a typically atypical day means knowing exactly what you need to conduct your work for maximum output. This often translates into accessing various forms of assistance. This idea is further elaborated by Bo, who owns a consulting company. He describes an array of individuals he can call upon to keep his work on track:

“... I have an 18-year-old son who is somewhat into programming... he does a little bit a work for me. I would meet with him sitting right here at my desk, and, you know, give him stuff to work on. And then our neighbor is... the wife of the couple, she was previously a programmer back before she had kids. And now her kids are like our kids and the oldest is a teenager or close, and so she's kinda getting back into working, and she's also doing a little bit a work for me as well. And so she might come over and, you know, I talk about work or give her some work to do."

In sum, flexibility is showcased in the fine details of technological and resource-based practice for the workers in our study. Utilizing the right mundane technology in a digital assemblage or leveraging the particular capability of a member of your social network allows you to not only bend as needed for a job, but, more importantly, to move forward past any potential chaos. Notably, this is a finding that does not relate to any one tool or piece of technology specifically. Rather, the common activity amongst all of our study subjects is an innovative form of technological and interpersonal bricolage.

\subsection{Flexible use of time and space}

Our data also confirm that flexible workers know how to manipulate time and space especially well. Often in response to their need for self-management, workers engage in an interesting set of spatio-temporal practices. One way they do this is by attempting to schedule or temporally outline their day for maximum productivity. This may sound a bit easier than it is because, in reality, most workers do not have typical days; their lives are far more random than not, which makes the achievement of finding temporal order all the more impactful. A different way of dealing with temporal flexibility is trying to find a pattern amongst the irregularity. Bob, a law partner, explains his typical day, 
which by the end of his explanation sounds more ordered than not. This is effect he is going for:

"I... do not have a typical day ... but if we want to kind of outline it, I will. I usually get up at about 4:00 am regularly. I try to go work out first thing in the morning, about 5:30 or 6:00. That doesn't always happen. (Laugh) Probably it doesn't happen. . . then I come back from doing that and then will do some... often do work at home if I don't have meetings first thing. But then, I am often off to the races as far as meetings or telephone calls, most days. And that will take up most of the day. And then I will eat dinner with my family, and then will put kids to bed, and then usually I'm ready to pass out at that point or get a little bit more work done."

For the flexible workers we interviewed, time is considered less as a resource to be spent wisely-the way most calendaring software would have you believe (Mazmanian et al. 2015)-and more of a contextual variable, like one's desktop, to be arranged in a way that is personally empowering or meaningful. The temporal randomness of one's professional life, in this sense, is tamed by fitting time into an individuated semantic scheme.

Similarly, we also discovered how workers manage spatial flexibility. A key way of doing this is to make yourself independent of all spatial constraints. Helen, a consultant, makes this point quite succinctly: "I work from wherever I need to, whether it's at home, in office, or, you know, kinda on the move." Like turtles, workers make themselves ready and able to work in any place at all; they bring their "offices" with them literally by carrying everything they need. Bob, the lawyer, recounts the contents of his bag for us, then puts these contents into a situated context for us: "I have a very small... messenger size bag that I put in my... iPad and, you know, a notebook to write on, and some... business cards and things like that, you know, and that's about it. That's, that's my office."

Beyond having the freedom to work from any locale is having the ability to work from any locale. Sam, a professional speaker and corporate trainer, does this by assigning certain types of work to certain types of spatial conditions, such as flying on an airplane. He explains:

"I do try while I'm on the airplane to maximize that airplane time, which means I try to, you know, preschedule either to write or to do some reading while I'm in the plane. I typically don't do internet on the airplane, because... the reliability of it just isn't strong enough. So I plan for my flight, and I'll make sure I have hard copy stuff, or something that I can write without logging on. You know, on Word or somethin' like that. So I don't typically use any Wi-Fi on the plane 'because it's expensive, and it's not reliable enough."

In sum, the flexible workers in our study leverage the freedom they have to work anytime, anywhere not merely by working from the beach occasionally, but by 
'knowingly' working in the places that they choose to inhabit. Some might say that these practices merely reflect an unfortunate blurring of the boundary between work and life or a loss in worker rights or safe workplace conditions ${ }^{4}$. Yet what came across most predominantly in our conversations with these workers were not these themes at all, and, we would hazard to guess, not because these individuals are workaholics in denial about the state of their professional lives. Rather, what appears to be a big part of being a flexible worker is having the opportunity to exercise agency in the face of ambiguity. This is a perspective on work that is inherently creative and strategic as it involves utilizing the resources to hand - technology, human resources, time, and space as well as one's own internal priorities and proclivities-in novel, yet highly situated ways.

\subsection{The emergent idea of elastic flexibility}

To explore this notion of agency further, we zeroed in on participants' accounts of flexibility in our data that were not responses to exogenous variables. For example, several individuals spoke about possessing a strategic orientation to their work that was proactive, not merely adaptive. Reflexive comments like this often superceded particular circumstances or episodes of problemsolving, and indicate, we assert, a type of intrinsic, intentional flexibility - something that we refer to provisionally as 'elasticity' - that should be considered further in discussions of flexible work. What distinguishes elasticity or elastic workers then? Somewhat imaginatively, we contend that, in addition to utilizing their flexible, turtle-like qualities, elastic workers possess the intelligence of a mimic octopus ${ }^{5}$ which allows them to shapeshift as needed. In other words, they possess an orientation to work that is both pre-emptive and reflexive.

In our data, we distinguish elastic flexibility from 'standard' flexibility in several ways. One way is in these workers' inclinations to always have a plan B in mind-a simultaneous acknowledgment that contingencies are everywhere and that nothing is black, white, nor straightforward. This means more than the ability to find an alternative solution or workaround, which might be considered a flexible skill, to being able to see what makes a set of alternative options equally operable. Sam, the corporate trainer and professional speaker, shows possession of this meta-level skill in his description of potential network connectivity options,

"So I can turn the iPhone on to be a hotspot if I'm in an area that doesn't have wi-fi and use that for the laptop or tablet. . . .I usually buy wi-fi in the hotel, or if the hotel is near a Starbucks, I go to Starbucks.”

\footnotetext{
${ }^{4}$ These are all important topics, indeed, and we do not disregard them in our analysis or consider them irrelevant.

${ }^{5}$ https://en.wikipedia.org/wiki/Mimic_octopus
} 
Likewise, Misaki, a freelance producer, shows that a pre-emptive orientation to the contingencies of flexible work relies not just on technical knowledge, but also experience:

"It's a pretty typical thing. In film it's that it will rain and the scene outside is supposed to be sunny, so what do you do? You revise the schedule and you figure out a way to shoot indoors that day. Again, it will cost money, but, like you know, hopefully you thought of this in advance. Another skill I have is sort of predicting in advance - but especially once you've done work for a while, you start to see the likely places where things are going to fuck up. So it's . . . the best project managers are ones who are both empathetic and respectful and smart and can move from 10,000 feet to 2 feet. When you do that then you can keep your eye on what's happening and how can we solve this problem."

Beyond knowledge and experience, the disposition towards elastic flexibility is strongly characterized by a worker's openness to learning. Helen exemplifies this motivation in her comments about continuously trying out new things, even while admitting a preference for tools that are comfortably familiar:

"I try different things. I try different things because my clients are gonna want to try all different things. So I try a multitude of services. My... biggest thing is SkyDrive which is now called OneDrive, because it's on Microsoft, because I've always been a Microsoft girl. Like I learned Microsoft since I was young. It's comfortable. I'm, you know, I know what it is, I've been certified in it, I've taken classes and classes and classes in it. I know it. So for me it's like putting myself outside the box, because I literally only got an iPhone because I've always been a Blackberry girl, and then they switched, you know Blackberry didn't keep up with the market, so new technology. But I had a client who said I will pay you to teach me how to use my iPhone or my iPad. Went yup, I'll be buying myself an iPhone and iPad. That's simple. And I just teach myself everything possible, and I'll read everything online, I'll look at YouTube videos."

Likewise, Todd, whose job as a columnist seems rather straightforward, nevertheless told us of his inclination toward tinkering when it came to the tools and processes he uses to document interviews:

"Well, I was doing this piece that was complicated, and... you know, typically, when I do a story, I would do it by phone, I would talk to someone, I would generally not talk to them for more than half an hour, and usually 20 minutes. I would take notes using a very cryptic shorthand that I was inventing on the fly, and then I would go back when I hung up the phone to those points of the conversation that I knew I wanted to use, and then I would go back and recreate those quotes. And that's how I operate mostly. . . . So recording the whole damn thing and 
having to listen to it and transcribe it, horribly inefficient. So what I was doing was... recording it, taking handwritten notes. When they said something I was gonna quote, marking the time down more or less, in the timer on my recorder when they said it, putting a little star next to it in my notes and moving on. So later, when I went through the recordings, I would go, fast forward to that point in time, and listen to it and just transcribe those bits."

These examples, while small and seemingly insignificant, indicate an important pattern about elasticity versus standard flexibility. Elastic workers appear to apply an agile methodology to themselves as subjects. They look at themselves in relation to their work by asking not "how can I get through this and back to something more standard and regular?" (i.e., the ability of someone with standard flexible skills) but rather "how can I improve myself as a worker when both standards and regularity are absent? How can I accommodate to irregularity as the standard?" While it is clear that engaging in flexible work practices over time facilitates the acquisition of a preemptive, learning-oriented perspective by a worker, it is unclear whether elastic workers have something intrinsically different that gets honed through experience over time. Our existing data are incomplete on this score, so we are currently in the process of designing a follow-on study to answer this question.

\section{Discussion}

Above, we used the metaphor of a turtle to describe the way that flexible workers enable themselves to work anywhere, anytime by carrying everything that they need with them (often on their backs, literally). By contrast, flexible workers with elasticity were metaphorically compared with mimic octopi. What does a mimic octopus do that is so remarkable? Sometimes it engages in shapeshifting efforts to protect itself, other times it lures in prey by making it appear as if they are a willing member of the opposite sex. In other words, they do what is needed in whatever situation they find themselves in, and they are rarely, if ever, in a situation to which they are not adapting.

Ciborra, the late organizational theorist, makes the claim that an octopus can accomplish such agility because of its intelligence. "[These] are intelligent practices," he says,

"the expression of a practical intelligence (Scribner 1984). Far from what has become the conventional distinction between tacit and explicit knowledge, practical intelligence is the metís of the Greek - the intelligence of the octopus: flexible, polymorphic, ambiguous, oblique, twisted, circular. This is the opposite of the straight, direct, rigid, and univocal character of the knowledge embedded in method. To orient oneself in the complex and changing world, dealing with forces that are too strong to be fully controlled, one needs to leverage the situation at hand 
by zig-zagging behavior, which never faced such forced up-front but accomplishes the project at hand with a sudden move of improvisation" (Ciborra 2004, p. 24).

In other words, it is not merely the ability to shapeshift that makes an octopus so effective in different situations, it is also their intelligence. In this case, we would describe intelligence not as the possession of a high-ranking IQ, but rather by the disposition an individual showcases to do two things repeatedly in relation to their work: strategize pre-emptively and continue learning proactively. This is what separates some flexible workers in our study from others.

What does the idea of the elastic worker mean for the continued study of work, especially in these liminal days of artificial intelligence and algorithmic management? Is the concept of the elastic worker soon to die from view when workers have less and less agency over their technological choices or when they cede that agency to a platform that can organize work in a personalized data-driven way? Will anyone need all of the improvisational intelligence of the octopus in the future? Of the many future questions that can and should be asked here, we focus on two in particular in this discussion. First, how does the notion of elastic flexibility inform our current understanding of flexible work writ large? Second, what are some of the potential design implications that come with this understanding of work? We address each of these questions in turn below.

\subsection{Building on elastic flexibility moving forward}

Most discussions of flexible work to date emphasize how individuals engage in practices that produce both temporary or long-term pockets of control or stability to be productive. They do this primarily in spatio-temporal ways and in the organization of work - both means that reflect the agency they possess to control these aspects of their professional lives. As a community, we have looked at the emergent phenomenon of flexible work with clear attention to detail, but have tended to classify workers and these work practices primarily by external markers. For example, workers are nomadic because they lack a fixed workplace, they are flexible because they are forced or choose to work during non-standard business hours or in contractual versus permanent positions, etc. Increasingly, these classifications are losing their discreteness as more and more people take on a combination of these classifiers all at once. As such, we need to address the construct of flexible work in a new way. We seek to offer an initial salvo in this direction by looking at the practice of flexibility almost as if it were a personality as well as a practice.

As the discussion of elastic workers above begins to intimate, flexibility is a cocreation between the external circumstances that define work and the experience and motivation of the worker (the intrinsic elements $\mathrm{s} /$ he brings to those circumstances). Elasticity is very much the combination of the work and worker here, which expresses itself in observable flexible practice but is not fully defined by those practices alone. When workers adapt to the exogenous pressures of their changing, 
dynamic environments, as detailed above, we should begin to ask more probingly about why they do these things in addition to how. We believe that the conversation surrounding flexible work would profit from greater curiosity about whether workers possess a personality or disposition that leads them to find the dynamic conditions of flexible work appealing or at least manageable. A worker's ability to organize his or her professional world(s) in a way that finds value, indeed generativity, in nonstandard practices is likely more than a skill or the result of experience alone.

The work that we present herein can augment our understanding of flexible work as it has been articulated in the literature by empirically verifying that flexibility is present in the practices of many types of knowledge workers today-particularly with regard to the creative uses of space, time, and infrastructure. Yet, while there are certain kinds of work that are easier for individuals to engage in non-traditionally (i.e., individuated, distributed, sequentiallyorganized forms of knowledge work such as copywriting, for example), not all copywriting, or similarly organized work, is flexible work. Instead, we would suggest that there is analytical purchase in considering the combination of task malleability coupled with the disposition of the worker as the best description of what it means to be 'flexible.'

Perhaps more pointedly, this research points to flexible work as a generative site for studying how and why workers learn to engage in the agile sociotechnical practices that they do. This can be done at the individual level, which we begin to do here, but it is also true that learning is a highly social activity, so this contention begs the question of looking at elastic flexibility from both the individual as well as the collective level. In this way, our nascent discussion of elasticity mirrors the way that the learning field has come to embrace 'learners' as opposed to students, looking both at individual's practices of learning as well as the ways that learners engage or are impacted by their environments (i.e., makerspaces, libraries, nature). The same approach could be taken by CSCW researchers in the future. The next steps in this direction could also move past the practice theoretical perspective - one which has been profitable to date - and embrace complementary methods from psychology or trace data ethnography to reveal these learning patterns both longitudinally and at various levels of analysis.

\subsection{Designing for integration}

As may have been evident throughout the paper, our research was not designed specifically to inform technology design. Yet, there are a few implications for design embedded within our more conceptual findings.

The first implication from our findings is that there is a need to design collaborative environments that either share common standards or design protocols, or can be easily reconfigured to accommodate different collaboration preferences. This consideration comes from the understanding that the future of work will continue to center highly on dynamic, distributed projects, as can already be seen in many 
domains, with an equally dynamic set of project collaborators who come together and disperse frequently. This claim echoes the way that many multinational companies are already configured (i.e., organized around distributed projects). Yet outside of this context, it is rare to see the use of shared management information systems. Outside of formal organizational contexts, workers turn to collaborative systems that have a common denominator quality (e.g., Google Docs). Tools like this become defaults because access does not rely on a particular organizational identity. Only a few other off-the-shelf collaborative systems, save some social media platforms, possess this combination of free access and collaborative utility. These data suggest that designing for these "common places"-metaphorically thinking of collaborative tools in environmental terms, like third places - might be a generative design challenge that accommodates some of the trends we are beginning to see with regard to the organization of work in the future.

The fact that Google makes it easy to integrate several of its subsystems together creates additional stickiness for workers. This leads us to our second design implication. Our data suggest that the use of Google products is not necessarily because of brand loyalty or even good design, but because workers can easily make a set of functional tools work together. Thus, one could say that one of the design implications of studying flexible work more closely is to see new design potential in the things that connect tools to one another-as we saw in the examples of Sam's use of a splitter and Smirity's use of a SIM card adapter. These 'integrators' act in ways that are typically overlooked, performing the invisible work of personalized, crafted infrastructures used by flexible workers. Thus, a key design focus for this community in the future could be to (re)consider the interstitial places where work is being done in addition to primary areas such as online collaboration spaces.

\subsection{Limitations}

Of course, there are notable limitations to this study. First, it is a limited sample in several ways, most obviously in the fact that the subjects are self-selected and all from one country (United States). Second, these insights rely primarily on a single method: interviews. This method cannot account well for longitudinal practices, nor situations where collaboration is occurring. Even so, it has proven an excellent approach for conducting exploratory work - our only claim here. Indeed, we have leveraged our original data set well, if we measure that claim by the follow-on studies that it has inspired. Finally, the sample skews toward a technological bias as this was the initial focus of the study. These data may be overrepresented in our findings as a result.

All of this being said, moving forward, we expect to emphasize future work that looks at how flexible workers collaborate while simultaneously managing themselves, their mobility in time and space, and their technology choices, in addition to probing further into considerations of worker personality and disposition. Doubtless, these moves will also inspire new questions, prompt the need to gather additional data, and produce new challenges to our extant notions of flexibility. 


\section{Conclusion}

This paper takes as its starting place the rich context of many knowledge workers today-highly distributed, increasing project focused, typically atypical days, infrastructural - and attempts to push past extant descriptions of this reality and these workers as 'flexible'. Amidst this compelling narrative we discover a set of workers who appear to possess a framework or disposition to work that is distinguished from others - a subclass of flexible workers that we call 'elastic' workers. We highlight these workers' preemptive stance in the face of professional ambiguity as well as their inclination to or adoption of perpetual learning practices. The contribution of this insight is twofold. First, we augment contemporary analyses of flexible knowledge work with empirical grist that begins to define how workers account for their own flexibility rather accepting a definition that stands primarily in contrast to traditional knowledge work standards. This advances our understanding of this phenomenon inductively rather than deductively. Second, our approach raises new questions for us as scholars and designers keen to exploit the conceptual and pragmatic intersection of technology and work. Less and less can we assume commonalities in practice at the level of industry or role in knowledge work domains. Rather, we need to look for different kinds of patterns and identify different classes of workers, which demands - in parallel — different methods for engaging in our work.

Nevertheless, it is clear that with the pace of change in trends, technology, and other influencing factors regarding knowledge work comes a need for workers to adapt and respond in new ways. Flexible workers work with seemingly invisible boundaries, but boundaries no less, except that these boundaries are porous, rather than solid. Said boundaries require an individual worker himself/herself to impose control, which, because of the personal nature of the task, varies greatly. In sum, it might be safe to say that all elastic workers are flexible, however not all flexible workers are elastic; at least not yet. The reason we feel this kind of possible new category of workers might be highly relevant to the field of computer-supported cooperative work is because we believe learning and evolution will continue to be vital both in this dynamic, ever changing world and well as in the future. Work is no longer just about having a skill or a particular set of skills, it goes beyond that to include a much wider scope of possibilities, creative thinking, and improvisations.

\section{Acknowledgements}

We would like to acknowledge the generosity of our interviewees in sharing their stories; prior collaborators, Mohammad Jarrahi and Steve Sawyer, for their analytical contributions; and the National Science Foundation for their generous support of this research.

Open Access This article is distributed under the terms of the Creative Commons Attribution 4.0 International License (http://creativecommons.org/licenses/by/4.0/), 
which permits unrestricted use, distribution, and reproduction in any medium, provided you give appropriate credit to the original author(s) and the source, provide a link to the Creative Commons license, and indicate if changes were made.

\section{References}

Alkhatib, Ali: Michael S. Bernstein; and Margaret Levi (2017). Examining Crowd Work and Gig Work Through The Historical Lens of Piecework. CHI '17. Proceedings of the $35^{\text {th }}$ Annual ACM Conference on Human Factors in Computing Systems, Denver, Colorado, 6-11 May 2017. New York, NY: ACM Press, pp. 4599-4616.

Allen, Tammy D.; Ryan C. Johnson; Kaitlin M. Kiburz; and Kristin M. Shockley (2013). WorkFamily Conflict and Flexible Work Arrangements: Deconstructing Flexibility. Personnel Psychology, vol. 66, no. 2, June 2013, pp. 345-376.

Barley, Stephen R.; and Gideon Kunda (2006a). Contracting: A New Form of Professional Practice. The Academy of Management Perspectives, vol. 20, no. 1, February 2006, pp. 45-66.

Barley, Stephen R.; and Gideon Kunda (2006b). Gurus, Hired Guns, and Warm Bodies: Itinerant Experts in a Knowledge Economy. Princeton, NJ: Princeton University Press.

Becker, Howard S. (2014). What About Mozart? What About Murder?: Reasoning From Cases. Chicago: University of Chicago Press.

Bellotti, Victoria; and Sara Bly (1996). Walking Away from the Desktop Computer: Distributed Collaboration and Mobility in a Product Design Team. CSCW '96. Proceedings of the 1996 ACM Conference on Computer Supported Cooperative Work, Boston, Massachusetts, 16-20 November, 1996. New York, NY: ACM Press, pp. 209-218.

Bouncken, Ricarda B.; and Andreas J. Reuschl (2016). Coworking-spaces: how a phenomenon of the sharing economy builds a novel trend for the workplace and for entrepreneurship. Review of Managerial Science, vol. 12, January 2018, no. 1, pp. 317-334.

Brandth, Berit; and Elin Kvande (2001). Flexible Work and Flexible Fathers. Work Employment And Society, vol. 15, June 2001, no. 2, pp. 251-267.

Brown, Barry; and Kenton O'Hara (2003). Place as a Practical Concern of Mobile Workers. Environment \& Planning A, vol. 35, September 2003, no. 9, pp. 1565-1587.

Brynjolfsson, Eric; and Andrew McAfee (2014). The Second Machine Age: Work, Progress, and Prosperity in a Time of Brilliant Technologies. New York, NY: W. W. Norton \& Company.

Carnoy, Martin. (2000). Sustaining the New Economy: Work, Family, and Community in the Information Age. New York, NY: Russell Sage Foundation.

Ciborra, Claudio. (2004). Encountering Information Systems as a Phenomenon. In Avgerou, Christine; Claudio Ciborra; and Frank Land (eds.) The Social Study of Information and Communication Technology: Innovation, Actors, and Contexts. Oxford: Oxford University Press, pp. 17-37.

Ciolfi, Luigina; and Aparecido Fabiano Pinatti de Carvalho (2014). Work Practices, Nomadicity and the Mediational Role of Technology. Computer Supported Cooperative Work (CSCW): The Journal of Collaborative Computing and Work Practices, vol. 23, April 2014, no. 2, pp. 119-136.

Ciolfi, Luigina; and Eleanor Lockley (2018). From Work to Life and Back Again: Examining the Digitally-Mediated Work/Life Practices of a Group of Knowledge Workers. Computer Supported Cooperative Work (CSCW): The Journal of Collaborative Computing and Work Practices, vol. 27, May 2018, no. 3, pp. 803-839. 
Ciolfi, Luigina; and Marc McLoughlin, M. (2017). Supporting Place-Specific Interaction through a Physical/Digital Assembly. Human-Computer Interaction, vol. 33, November 2017, no. 5-6, pp. 499-543.

Ciolfi, Luigina; and Breda Gray; and Anthony D'Andrea (2012). Social Aspects of Place Experience in Mobile Work/Life Practices. In Dugdale, Julie; Cedric Masclet; Maria Antoinetta Grasso; JeanFrancois Boujut; and Parina Hassanaly (eds.) From Research to Practice in the Design of Cooperative Systems: Results and Open Challenges. London: Springer Verlag, pp. 183-196.

Cnossen, Boukje; and Nicolas Bencherki (2018). The Role of Space in the Emergence and Endurance of Organizing: How Independent Workers and Material Assemblages Constitute Organizations. Human Relations, September 2018, pp. 1-24.

Cousins, Karlene; and Daniel Robey (2015). Managing Work-Life Boundaries with Mobile Technologies: An Interpretive Study of Mobile Work Practices. Information Technology \& People, vol. 28 , no. 1, pp. 34-71.

Czarniawska, Barbara (2013). Nomadic Work as Life-Story Plot. Computer Supported Cooperative Work (CSCW): The Journal of Collaborative Computing and Work Practices, vol. 23, April 2014, no. 2, pp. 205-221.

D'Mello, Marisa; and Sundeep Sahay (2007). "I am kind of a nomad where I have to go places and places"... Understanding Mobility, Place and Identity in Global software Work from India. Information and Organization, vol. 17, June 2007, no. 3, pp. 162-192.

Davenport, Thomas H. (2005). Thinking for a Living: How to Get Better Performances And Results from Knowledge Workers. Cambridge, MA: Harvard Business Review Press.

Davies, Andrea Rees; and Brenda D. Frink (2014). The Origins of the Ideal Worker: The Separation of Work and Home in the United States From the Market Revolution to 1950. Work and Occupations, vol. 41, February 2014; no. 1, pp. 18-39.

de Carvalho, Aparecido Fabiano Pinatti (2014). Collaborative Work and Its Relationship to Technologically-Mediated Nomadicity. In Rossitto, Chiara; Luigina Ciolfi; David Martin; and Bernard Conein (eds.), COOP 2014. Proceedings of the 11th International Conference on the Design of Cooperative Systems, 27-30 May 2014, Nice (France). Cham, Switzerland: Springer International Publishing, pp. 209-224.

de Carvalho, Aparecido Fabiano Pinatti; Luigina Ciolfi; and Breda Gray (2017). Detailing a Spectrum of Motivational Forces Shaping Nomadic Practices. CSCW'17. Proceedings of the 2017 ACM Conference on Computer Supported Cooperative Work and Social Computing, Portland, Oregon, 25 February-1 March, 2017. New York, NY: ACM Press, pp. 962-977.

de Peuter, Grieg (2011). Creative Economy and Labor Precarity: A Contested Convergence. Journal of Communication Inquiry, vol. 35, October 2011, no. 4, pp. 417-425.

Ekbia, Hamid; and Bonnie Nardi (2014). Heteromation and its (Dis)contents: The Invisible Division of Labor between Humans and Machines. First Monday, vol. 19, May 2014, no. 6, https://doi.org/ 10.5210/fm.v19i6.5331.

Erickson, Ingrid; and Mohammad Hossein Jarrahi (2016). Infrastructuring and the Challenge of Dynamic Seams in Mobile Knowledge Work. CSCW '16. Proceedings of the 19th ACM Conference on Computer-Supported Cooperative Work \& Social Computing, San Francisco, California, 27 February-2 March 2016. New York, NY: ACM Press, pp. 1323-1336.

Erickson, Ingrid (2017). Working, Being, and Researching in Place: A Mixed Methodological Approach for Understanding Digital Experiences. In Mir, Raza; and Sanjay Jain (eds.) The Routledge Companion to Qualitative Research in Organization Studies. New York, NY: Routledge, pp. 291-305.

Felstead, Alan; and Nick Jewson (1999). Global Trends in Flexible Labour. London: Macmillan International Higher Education.

Francisco, Rosemary; Amarolinda Zanela Klein; Yrjö Engeström; and Annalisa Sannino (2018). Knowledge on the Move: Expansive Learning Among Mobile Workers. In Kolbaek, Ditte (ed.) 
Online Collaboration and Communication in Contemporary Organizations, Hershey, PA: IGI Global, pp. 179-200.

Gandini, Alessandro (2016). The Reputation Economy: Understanding Knowledge Work in Digital Society. London: Palgrave Macmillan UK.

Glaser, Bernard. G.; and Anselm L. Strauss (2017). Discovery of Grounded Theory: Strategies for Qualitative Research. New York: Routledge.

Garrett, Lyndon E.; Gretchen M. Spreitzer; and Peter A. Bacevice (2017). Co-constructing a Sense of Community at Work: The Emergence of Community in Coworking Spaces. Organization Studies, vol. 38, June 2017, no. 6, pp. 821-842.

Gisin, Leila; Hartmut Schulze; and Barbara Degenhardt (2016). Boundary Management as a Crucial Success Factor for Flexible-Mobile Work, Demonstrated in the Case of Home Office. In Deml, Barbara; Patricia Stock; Ralph Bruder; and Christopher Marc Schlick (eds.), Advances in Ergonomic Design of Systems, Products and Processes, Berlin: Springer Verlag Berlin Heidelberg, pp. 375-394.

Glaser, Bernard; and Anselm L. Strauss (1967). Discovery of Grounded Theory: Strategies for Qualitative Research. Philadelphia, PA: Aldine Publishing Company.

Gregg, Melissa (2013). Work's Intimacy. New York, NY: John Wiley \& Sons.

Grudin, Jonathan (1994). Computer-Supported Cooperative Work: History and Focus. Computer, vol. 27, May 1994, no. 5, pp. 19-26.

Gumienny, Raja; Lutz Gericke; Matthias Wenzel; and Christoph Meinel (2013). Supporting Creative Collaboration in Globally Distributed Companies. CSCW '13. Proceedings of the $16^{\text {th }}$ ACM Conference on Computer Supported Cooperative Work and Social Computing, San Antonio, Texas, 23-27 February, 2013. New York, NY: ACM Press, pp. 995-1007.

Harmer, Brian M.; and David J. Pauleen (2012). Attitude, Aptitude, Ability and Autonomy: The Emergence of "Offroaders", a Special Class of Nomadic Worker. Behaviour \& Information Technology, vol. 31, July 2010, no. 5, pp. 439-451.

Heath, Christian; Paul Luff; and Abigail Sellen (1995). Reconsidering the Virtual Workplace: Flexible Support for Collaborative Activity. In Marmolin, Hans; Yngve Sundblad; and Kjeld Schmidt (eds.): ECSCW 1995. Proceedings of the Fourth European Conference on Computer-Supported Cooperative Work, Dordrecht: Springer Science+Business Media, pp. 83-99.

Hill, E. Jeffrey; Alan J. Hawkins; Maria Ferris; and Michelle Weitzman (2001). Finding an Extra Day a Week: The Positive Influence of Perceived Job Flexibility on Work and Family Life Balance. Family Relations, vol. 50, January 2001, no. 1, pp. 49-58.

Hill, E. Jeffrey; Jenet Jacob Erickson; Erin K. Holmes; and Maria Ferris (2010). Workplace Flexibility, Work Hours, and Work-Life Conflict: Finding an Extra Day or Two. Journal of Family Psychology, vol. 24, June 2010, no. 3, pp. 349-358.

Hinds, Pamela; and Sara Kiesler (2002). Distributed Work. Cambridge, MA: The MIT Press.

Howcroft, Debra; and Birgitta Bergvall-Kåreborn (2018). A Typology of Crowdwork Platforms. Work Employment and Society, vol. 33, May 2018, no. 1, pp. 21-38.

Humphry, Justine (2014). Officing: Mediating Time and the Professional Self in the Support of Nomadic Work. Computer Supported Cooperative Work (CSCW): The Journal of Collaborative Computing and Work Practices, vol. 23, April 2014, no. 2, pp. 185-204.

Jarrahi, Mohammad Hossein; and Sarah Beth Nelson (2018). Agency, Sociomateriality, and Configuration Work. The Information Society, vol. 34, June 2018, no. 4, pp. 244-260.

Jarrahi, Mohammad Hossein; Sarah Beth Nelson; and Leslie Thomson (2017). Personal Artifact Ecologies in the Context of Mobile Knowledge Workers. Computers in Human Behavior, vol. 75, October 2017, pp. 469-483.

Jarrahi, Mohammad Hossein; Gabriela Philips; Will Sutherland; Steve Sawyer; and Ingrid Erickson (2019). Personalization of Knowledge, Personal Knowledge Ecology, and Digital Nomadism. 
Journal of the Association for Information Science \& Technology, vol. 70, April 2019, no. 4, pp. 313-324.

Kakihara, Masao; and Carsten Sørensen (2001). Expanding the "Mobility" Concept. ACM SIGGROUP Bulletin, vol. 22, December 2001, no. 3, pp. 33-37.

Kalleberg, Arne L. (2000). Nonstandard Employment Relations: Part-Time, Temporary and Contract Work. Annual Review of Sociology, vol. 26, August 2000, pp. 341-365.

Kalleberg, Arne L. (2018). Precarious Lives: Job Insecurity and Well-Being in Rich Democracies. New York, NY: John Wiley \& Sons.

Kelliher, Clare; and Dierdre Anderson (2010). Doing More with Less? Flexible Working Practices and the Intensification of Work. Human Relations, vol. 63, January 2010, no. 1, pp. 83-106.

Kietzmann, Jan; Kirk Plangger; Ben Eaton; Kerstin Heilgenberg; Leyland Pitt; Pierre Berthon (2013). Mobility at Work: A Typology of Mobile Communities of Practice and Contextual Ambidexterity. The Journal of Strategic Information Systems, vol. 22, December 2013, no. 4, pp. 282-297.

Kleinrock, Leonard (1996). Nomadicity: Anytime, Anywhere in a Disconnected World. Mobile Networks and Applications, vol. 1, December 1996, no. 4, pp. 351-357.

Koroma, Johanna; and Matti Vartiainen (2018). From Presence to Multipresence: Mobile Knowledge Workers' Densified Hours. In Stephanie Taylor and Susan Luckman (eds.) The New Normal of Working Lives: Critical Studies in Contemporary Work and Employment, London: Palgrave Macmillan, pp. 171-200.

Koroma, Johanna; Ursula Hyrkkänen; and Matti Vartiainen (2014). Looking for People, Places and Connections: Hindrances When Working in Multiple Locations: A Review. New Technology, Work and Employment, vol. 29, July 2014, no. 2, pp. 139-159.

Leclercq-Vandelannoitte, Aurelie; and Henri Isaac (2016). The New Office: How Coworking Changes the Work Concept. The Journal of Business Strategy, vol. 37, no. 6, pp. 3-9.

Levi-Strauss, Claude (1966). The Savage Mind. Chicago, IL: University of Chicago Press.

Liegl, Michael (2014). Nomadicity and the Care of Place - on the Aesthetic and Affective Organization of Space in Freelance Creative Work. Computer Supported Cooperative Work (CSCW): The Journal of Collaborative Computing and Work Practices, vol. 23, April 2014, no. 2, pp. 163-183.

Mazmanian, Melissa; and Ingrid Erickson (2014). The Product of Availability: Understanding the Economic Underpinnings of Constant Connectivity. CHI '14. Proceedings of the $32^{\text {nd }}$ Annual ACM Conference on Human Factors in Computing Systems, Toronto, Ontario, 26 April-1 May, 2014. New York, NY: ACM Press, pp. 763-772.

Mazmanian, Melissa; Wanda J. Orlikowski; and JoAnne Yates (2013). The Autonomy Paradox: The Implications of Mobile Email Devices for Knowledge Professionals. Organization Science, vol. 24, February 2013, no. 5, pp. 1337-1357.

Mazmanian, Melissa; Ingrid Erickson; and Ellie Harmon (2015). Circumscribed Time and Porous Time: Logics As a Way of Studying Temporality. CSCW '15. Proceedings of the 18th ACM Conference on Computer Supported Cooperative Work \& Social Computing, Vancouver, BC, 14-18 March, 2015. New York, NY: ACM Press, pp. 1453-1464.

McNall, Laurel A.; Aline D. Masuda; and Jessica M. Nicklin (2010). Flexible Work Arrangements, Job Satisfaction, and Turnover Intentions: The Mediating Role of Work-to-Family Enrichment. The Journal of Psychology, vol. 144, July 2010, no. 1, pp. 61-81.

Milkman, Ruth; and Edward Ott (2014). New Labor in New York: Precarious Workers and the Future of the Labor Movement. Ithaca, NY: Cornell University Press.

Morse, Janice M.; Phyllis Noerager Stern; Juliet Corbin; Barbara Bowers; Kathy Charmaz; and Adele Clarke (2016). Developing Grounded Theory: The Second Generation. New York, NY: Routledge.

Mullan, Killian; and Judy Wajcman (2017). Have Mobile Devices Changed Working Patterns in the 21st Century? A Time-Diary Analysis of Work Extension in the UK. Work Employment And Society, vol. 33, October 2017, no. 1, pp. 3-20. 
Nylén, Daniel; Jonny Holmström; and Kalle Lyytinen (2014). Oscillating Between Four Orders of Design: The Case of Digital Magazines. Design Issues, vol. 30, July 2014, no. 3, pp. 53-68.

Origgi, Gloria (2017). Reputation: What It Is and Why It Matters. Princeton, NJ: Princeton University Press.

Orlikowski, Wanda J. (2000). Using Technology and Constituting Structures: A Practice Lens for Studying Technology in Organizations. Organization Science, vol. 1, August 2000, no. 4, pp. 404428.

Osnowitz, Debra (2010). Freelancing Expertise: Contract Professionals in the New Economy. Ithaca, NY: Cornell University Press.

Perlow, Leslie A.; and Erin L. Kelly (2014). Toward a Model of Work Redesign for Better Work and Better Life. Work and Occupations, vol. 4, February 2014, no. 1, pp. 111-134.

Perry, Mark; Kenton O’Hara; Abigail Sellen; Barry Brown; and Richard Harper (2001). Dealing with Mobility: Understanding Access Anytime, Anywhere. ACM Transactions on Computer-Human Interaction (TOCHI), vol. 8, December 2001, no. 4, pp. 323-347.

Pipek, Volkmar; and Volker Wulf (2009). Infrastructuring: Toward an Integrated Perspective on the Design and Use of Information Technology. Journal of the Association for Information Systems, vol. 10, May 2009, no. 5, pp. 447-473.

Pittinsky, Todd L.; and Margaret J. Shih (2004). Knowledge Nomads: Organizational Commitment and Worker Mobility in Positive Perspective. The American Behavioral Scientist, vol. 47, February 2004, no. 6, pp. 791-807.

Prassl, Jeremias. (2018). Humans as a Service: The Promise and Perils of Work in the Gig Economy. Oxford: Oxford University Press.

Reichenberger, Ina (2018). Digital Nomads - A Quest for Holistic Freedom in Work and Leisure. Annals of Leisure Research, vol. 21, July 2017, no. 3, pp. 364-380.

Richardson, Julia (2010). Managing Flexworkers: Holding On and Letting Go. Journal of Management Development, vol. 29, no. 2, pp. 137-147.

Richardson, Julia; and Steve McKenna (2014). Reordering Spatial and Social Relations: A Case Study of Professional and Managerial Flexworkers. British Journal of Management, vol. 25, March 2013, no. 4, pp. 724-736.

Rossitto, Chiara; and Airi Lampinen (2018). Co-Creating the Workplace: Participatory Efforts to Enable Individual Work at the Hoffice. Computer Supported Cooperative Work (CSCW): The Journal of Collaborative Computing and Work Practices, vol. 27, December 2018, nos. 3-6, pp. 947-982.

Rossitto, Chiara; Cristian Bogdan; and Kerstin Severinson-Eklundh (2014). Understanding Everyday Cognition. Cambridge, MA: Harvard University Press, pp 13-31.

Sayah, Shiva (2013). Managing Work-Life Boundaries with Information and Communication Technologies: The Case of Independent Contractors. New Technology, Work and Employment, vol. 28, November 2013, no. 3, pp. 179-196.

Scribner, Sylvia (1984). Studying Working Intelligence. Rogoff, Barbara; and Jean Lave (eds.) In Everyday Cognition. Cambridge, MA: Harvard University Press, pp13-31

Shockley, Kristen M.; and Tammy D. Allen (2007). When Flexibility Helps: Another Look at the Availability of Flexible Work Arrangements and Work-Family Conflict. Journal of Vocational Behavior, vol. 71, December 2007, no. 3, pp. 479-493.

Simonton, Deborah; and Anne Montenach (2018). A cultural history of work: Volumes 1-6. London: Bloomsbury Academic.

Spillman, Lyn; and Sorcha A. Brophy (2018). Professionalism as a Cultural Form: Knowledge, Craft, and Moral Agency. Journal of Professions and Organization, vol. 5, July 2018, no. 2, pp. 155-166.

Spinuzzi, Clay (2012). Working Alone Together: Coworking as Emergent Collaborative Activity. Journal of Business and Technical Communication, vol. 26, May 2012, no. 4, pp. 399-441. 
Spinuzzi, Clay (2015). All Edge: Inside the New Workplace Networks. Chicago, IL: University of Chicago Press.

Standing, Guy (2011). The Precariat: The New Dangerous Class. Edinburgh: A\&C Black.

Su, Norman M.; and Gloria Mark (2008). Designing for Nomadic Work. DIS '08. Proceedings of the 7th ACM Conference on Designing Interactive Systems, Cape Town, South Africa, 25-27 February, 2008. New York, NY: ACM Press, pp. 305-314.

Tilson, David; Kalle Lyytinen; and Carsten Sørensen (2010). Digital Infrastructures: The Missing IS Research Agenda. Information Systems Research, vol. 21, December 2010, no. 4, pp. $748-759$.

Vertesi, Janet (2014). Seamful Spaces: Heterogeneous Infrastructures in Interaction. Science, Technology \& Human Values, vol. 39, January 2014, no. 2, pp. 264-284.

Wajcman, Judy; Michael Bittman; and Judith E. Brown (2008). Families without Borders: Mobile Phones, Connectedness and Work-Home Divisions. Sociology, vol. 42, August 2008, no. 4, pp. 635-652.

Wood, Alex J.; Mark Graham; Vili Lehdonvirta; and Isis Hjorth (2018). Good Gig, Bad Big: Autonomy and Algorithmic Control in the Global Gig Economy. Work Employment and Society, vol. 33, August 2018, no. 1, pp. 56-75.

Yuan, Yufei; Norm Archer; Catherine E. Connelly; and Wuping Zheng (2010). Identifying the Ideal Fit between Mobile Work and Mobile Work Support. Information \& Management, vol. 47, April 2010, no. 3, pp. 125-137.

Publisher's Note Springer Nature remains neutral with regard to jurisdictional claims in published maps and institutional affiliations. 